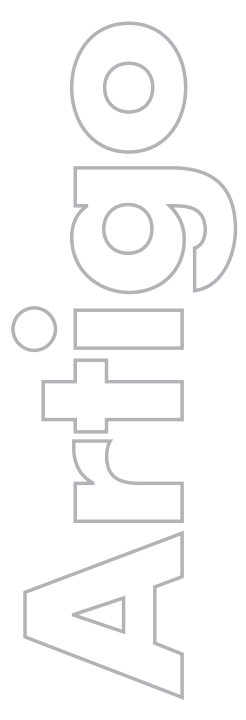

revista

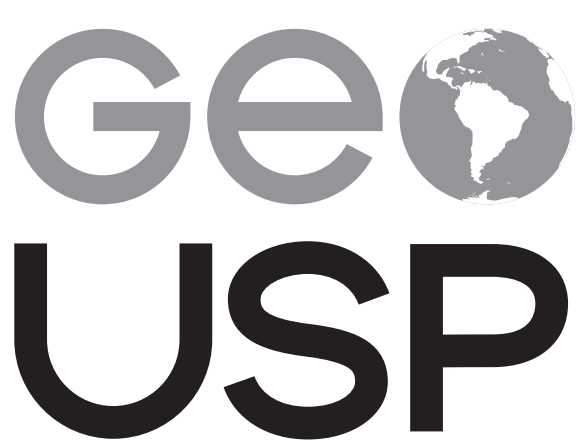

espaço e tempo

Volume $21 \cdot n^{\circ} 3$ (2017)

ISSN 2179-0892
O Sistema Único de Saúde (SUS) como um macrossistema: território, técnica e política

Luis Henrique Leandro Ribeiro

FFP-UERJ

p. $737-754$

Como citar este artigo:

RIBEIRO, L. H. L. O Sistema Único de Saúde (SUS) como um macrossistema: território, técnica e política. Geousp - Espaço e Tempo (Online), v. 21, n. 3, p. 737-754, dez. 2017. ISSN 2179-0892.

Disponível em: <http://www.revistas.usp.br/geousp/ article/view/118291>. doi: 10.11606/issn.2179-0892. geousp.2017.118291.

\section{(c) $(1)(9$}

Este artigo está licenciado sob a Creative Commons Attribution 4.0 License. 


\title{
O Sistema Único de Saúde (SUS) como um macrossistema: território, técnica e política
}

\section{Resumo}

O Sistema Único de Saúde (SUS) constitui um macrossistema no território brasileiro ao agregar ampla e diversa materialidade, organizando e gerenciando seus fluxos. Ademais, dois atributos o distinguem: grande sensibilidade às especificidades dos lugares e centralização e descentralização técnica e política das ações. A dimensão macro é o SUS, o que leva a compreendê-lo para além de um sistema de saúde, por meio de particularidades como: a multidimensionalidade, que engloba elementos de outras instâncias da vida (social, econômica, cultural e política); a gama diversa e desigual de atores (estatais e não estatais) que o move e aos sentidos de suas ações; e a transescalaridade de sua concreção nos lugares (nexos locais, nacionais e internacionais). Como infraestrutura da vida cotidiana, é um macrossistema hegemônico atuando sobre as condições objetivas (tecnoesfera) e subjetivas (psicoesfera) da existência, concepção que tem importantes implicações na política de saúde e na integração do território.

Palavras-chave: Território. Saúde. Macrossistema. Sistema Único de Saúde (SUS).

\section{The Unified Health System (SUS) as a large technological system: territory, technique and politic}

\begin{abstract}
The Unified Health System (SUS) constitutes a large technological system within the Brazilian territory since it aggregates a broad and diverse materiality in organizing and managing its flows. Additionally, it has two other attributes that make it unique: high sensibility to specificities of different places; and technical and political centralization and decentralization of its actions. The macro dimension is the SUS, leading it to be understood not simply as a health system, through its: multidimensionality - elements of other life instances (social, economic, cultural and political); broad and unequal spectrum of actors (state and non-state) who move it and the meanings of its actions; and the trans-scaleness of its concretion in places (local, national and international nexuses). As an infrastructure
\end{abstract}


of everyday life, it is a hegemonic large technological system that acts upon objective (technosphere) and subjective (psychosphere) conditions of existence, a conception that has important implications for health policy and territory integration.

Keywords: Territory. Health. Large Technological System. Unified Health System (SUS).

\section{Introdução}

A Lei n. 8.080, de 19 de setembro de 1990, que regulamenta o SUS define em seu Artigo 4 o sistema de saúde como o "conjunto de ações e serviços de saúde, prestados por órgãos e instituições públicas federais, estaduais e municipais, da Administração direta e indireta e das fundações mantidas pelo Poder Público" (Brasil, 1990), incluindo "as instituições públicas federais, estaduais e municipais de controle de qualidade, pesquisa e produção de insumos, medicamentos, inclusive de sangue e hemoderivados, e de equipamentos para saúde" (parágrafo lo), além de definir que a "iniciativa privada poderá participar do Sistema Único de Saúde (SUS), em caráter complementar" (parágrafo $2^{\circ}$ ).

Segundo Lobato e Giovanella (2012, p. 101) o sistema de serviços de saúde - entendido como o "conjunto de organizações responsáveis pelas ações e pelos serviços dirigidos à prevenção, à recuperação e à promoção à saúde de uma dada população" - é um dos componentes do sistema de saúde. Para os autores, o sistema de saúde é um conceito mais amplo compreendido como:

[...] conjunto de relações políticas, econômicas e institucionais responsáveis pela condução dos processos referentes à saúde de uma dada população que se concretizam em organizações, regras e serviços que visam a alcançar resultados condizentes com a concepção de saúde prevalecente na sociedade. (Lobato; Giovanella, 2012, p. 89)

Lobato e Giovanella (2012) assinalam que todo sistema de saúde é estruturado a partir de quatro funções: (i) financiamento (mecanismos e critérios de distribuição e alocação dos recursos financeiros); (ii) prestação de serviços (modalidades de serviços, modelos de atenção); (iii) gestão (formulação de políticas, planejamento, financiamento, contratação e controle e avaliação); e (iv) regulação (marcos legais e normativos que regulam prestadores de serviços, vigilância sanitária e mercado em saúde).

A dinâmica de um sistema de saúde é dada pelas relações - mediadas pelas quatro funções - estabelecidas entre si pelos seus componentes: (i) cobertura (população atendida e rol de serviços); (ii) financiamento (recursos disponíveis que sustentam sistema); (iii) força de trabalho (profissionais, técnicos e trabalhadores); (iv) rede de serviços (coletivos ou de assistência médica individual); (v) insumos (equipamentos, medicamentos e suprimentos para exames diagnósticos); (vi) tecnologia e conhecimento (conhecimento e produção de insumos); e (vii) organizações (estruturas responsáveis pela regulação, gestão e administração do sistema). 
sistema de saúde pode ser compreendido como um sistema técnico, que, conforme definido por Ellul (1977, p. 88), é um "conjunto de elementos em relação uns com os outros de tal modo que toda evolução de um elemento provoca uma evolução do conjunto, e toda modificação do conjunto repercute sobre cada elemento". Embora os sistemas entrem em relação uns com os outros, os elementos que compõem um sistema têm a tendência de se relacionarem preferencialmente entre si do que se relacionarem com elementos externos. Um sistema técnico - que nunca é estático e está sempre em transformação - apresenta duas dimensões fundadoras: uma que é dada pelas inter-relações entre os principais e mais significativos elementos do conjunto, que dá sua coerência interna; e outra constituída pela relação orgânica do sistema com o mundo exterior, logo, necessariamente aberto e dinâmico.

Para Hughes $(1983,2008)$, um sistema constitui um hibrido, uma relação indissociável e recíproca entre distintos componentes tanto técnicos como institucionais, um sistema sociotécnico que resulta causa e efeito do movimento histórico-social. Os grandes sistemas técnicos tendem ao equilibrio e expansão permanentes, cooptando e racionalizando as demais técnicas fora de seu sistema. Para o autor é a pluralidade de redes que caracteriza um macrossistema cujo elemento distintivo é o seu poder, termo que na língua inglesa (power) integra duas acepções: poder político (meio de jogar com forças sociais) e potência motriz (meio de aumentar as forças produtivas e fazer circular).

conceito de macrossistema técnico é utilizado comumente para estudos em outras áreas que não a da saúde, como a energética e a viária (Hughes, 1983; Gras, 1997; Santos, 1999; Cataia, 2014). No Brasil, o conceito de macrossistema técnico é tratado na geografia por Milton Santos (1999), em 1996, para se referir aos grandes sistemas técnicos "sem os quais os outros sistemas técnicos não funcionariam. Os macrossistemas técnicos promovem grandes trabalhos (barragens, vias rápidas de transporte terrestre, aeroportos, telecomunicações etc.)", constituindo "o fundamento material das redes de poder" (Santos, 1999, p. 142).

Questiona-se: o SUS pode ser compreendido como um macrossistema de saúde do território brasileiro? O objetivo do artigo é apresentar a tese de que o SUS é um macrossistema (técnico e político) presente no cotidiano da população no Brasil, ainda que muitas vezes não seja percebido, constituído pela integração de diversas redes e sistemas técnicos, sem os quais muitas outras técnicas não podem se instalar e funcionar e, com o qual, diversas outras técnicas vinculadas à saúde têm de lidar, como é o caso das práticas populares de saúde e as chamadas medicinas alternativas e complementares (Ribeiro, 2015). O SUS não é apenas um grande sistema ou conjunto de sistemas, mas macro no sentido de expressar uma força de arrasto e de ser o fundamento material das redes de poder (Raffestin, 1993; Santos, 1999).

$\bigcirc$ artigo apresenta a definição e os pré-requisitos do SUS como macrossistema de saúde, com dados que embasam sua magnitude e hegemonia no território brasileiro, seguidos da análise do SUS como infraestruturas da vida cotidiana e os sentidos de suas sistematicidades. Por fim, as conclusões.

\section{Definições e pré-requisitos do SUS como um macrossistema de saúde}

Um macrossistema técnico pode ser basicamente definido pela presença de três elementos (Gras, 1997): (i) um objeto industrial, em seu sentido amplo (como uma usina nuclear ou uma hidrelétrica); (ii) uma organização da distribuição dos fluxos (como uma rede elétrica); e (iii) uma empresa 
de gestão comercial para fazer a ligação entre a oferta e a demanda. Uma característica marcante do macrossistema técnico apontada pela literatura (Hughes, 1983, 2008; Hughes; Mayntz, 1988; Joerges, 1988; Braun; Joerges, 1992; Gras, 1993, 1997) é o fato de ser insensível às especificidades dos lugares. $\bigcirc$ que eleva um grande sistema técnico à condição de macro, é sua estrutura de poder, que envolve a capacidade de regular fluxos, isto é, um poder motriz ou força de circulação (de ideias, signos, objetos, bens e pessoas) e um poder político de constituir redes de alianças e interesses.

Pode-se considerar que alguns macrossistemas apresentam um caráter mais estratégico e uma condição mais necessária, como o elétrico e o de comunicação que além de garantirem o funcionamento de todos os outros macrossistemas também garantem a produção, distribuição e uso da maioria dos bens e serviços da maior parte das organizações das sociedades atuais: saúde, proteção social, cultura e lazer, segurança e ordem pública, ciência e educação, religião e vida comunitária.

Consideramos o SUS um macrossistema técnico estratégico e vital. Tal como os demais, ele preenche os três requisitos básicos de um macrossistema: (i) fixos de saúde (no sentido amplo desses objetos: unidades básicas, ambulatórios, hospitais, laboratórios, equipamentos médicos, medicamentos, meios de transporte); (ii) animados por ações de atores e agentes que organizam a distribuição dos fluxos entre esses fixos (referência e contra referência entre os níveis de atenção à saúde - básica, média e alta complexidade - além de apoio diagnóstico e terapêutico); e (iii) um órgão de gestão da oferta e demanda que, no caso do SUS, é centralizado em algumas políticas (União) e descentralizado na maior parte das ações (estados, Distrito Federal e municípios).

Ademais, o SUS é sensível às especificidades dos lugares, o que o distingue dos macrossistemas técnicos mais consagrados, mas, assim como esses, é um sistema técnico macro porque hegemônico, ou seja, porque chega ao cotidiano das pessoas e porque referencia objetiva e subjetivamente, ainda que em graus e combinações distintos, toda prática ou sistema de saúde no território brasileiro. Um movimento permanente marcado por uma multiplicidade de combinações de objetos e ações em saúde e dotado de grande capacidade de adaptação. Muito vinculado e sensível às particularidades dos lugares cujos estímulos internos e externos - constitutivos de situações geográficas únicas - produz e reproduz constantemente o macrossistema de saúde brasileiro.

A dimensão macro é o SUS, o que permite tanto o exercício da concepção ampliada de saúde (em suas distintas determinações e sentidos) quanto compreendê-lo para além de um sistema de saúde, por meio de sua multidimensionalidade (elementos de outras instâncias da vida - social, econômica, cultural e política), da gama diversa e desigual de atores (estatais e não estatais) que o move e os sentidos de suas ações e da transescalaridade de sua concreção nos lugares (nexos locais, nacionais e internacionais).

Ademais, o SUS é macro devido aos feitos notáveis e extraordinários, mas também no que tem de corriqueiro e desapercebido, ou seja, em suas invisibilidades. Como infraestrutura da vida cotidiana, o macrossistema é hegemônico, pois atua sobre as condições objetivas (tecnoesfera) e subjetivas (psicoesfera) da existência.

macrossistema de saúde se caracteriza pela pluralidade de redes técnicas e políticas, de organizações e centros de comando, pelas diversas escalas de ação e dos fluxos, e pela capacidade de se moldar ou ser moldado pelo conteúdo dos lugares. A pluralidade, alcance e heterogenei- 
dade dos componentes e redes constitutivos, integrados ou mobilizados no âmbito do macrossistema de saúde no Brasil podem ser organizados da seguinte maneira: (i) estabelecimentos de saúde (unidades básicas de saúde, ambulatórios, clínicas de diagnóstico, consultórios, pronto-socorro, unidades de pronto atendimento, hospitais); (ii) prestadores de serviços de saúde (administração pública direta ou indireta, grupos privados, filantrópicos, religiosos, Santas Casas, Organizações de Saúde, Organizações Não Governamentais); (iii) redes assistenciais (redes temáticas, redes de atenção, rede de transplantes de órgãos, de urgências e emergências, redes integradas de atenção); (iv) telecomunicação (centrais de regulação de referência e contra referência, de chamados de urgência, de alertas); (v) educação e formação (universidades, formação de especialidades, capacitação, programa de residência médica); (vi) pesquisa (a plataforma Registro Brasileiro de Ensaios Clínicos, a ReBEC, universidades, centros, institutos, fundações e laboratórios de pesquisa e desenvolvimento); (vii) informação (Datasus, Sistema de Informações Hospitalares e vários outros); (viii) insumos (laboratórios públicos e privados produtores de insumos farmacêuticos, medicamentos, vacinas e biológicos); (ix) equipamentos médico, hospitalares e odontológicos (empresas produtoras dos mais diversos artigos, utensilios, ferramentas e equipamentos); ( $\mathrm{x}$ ) transportes (rede de atendimento móvel de urgência e emergência, rede frio de vacinas, transporte aéreo de radiofármacos e de órgãos, barcos fluviais para atendimento médico-assistencial); (xi) defesa (defesa civil e vigilância sanitária e epidemiológica); (xii) população (usuários do sistema assistencial, conselhos participativos, de controle social, movimentos sociais e sociedade civil organizada); (xiii) profissionais (técnicos e gestores da área da saúde e de outras áreas da administração pública e privada; organizações e associações profissionais) e; (xiv) representantes politicos (poder judiciário e poderes executivo e legislativo dos entes municipal, estadual e federal, além de partidos políticos, lobistas e organismos internacionais).

O macrossistema é, portanto, um grande comunicador que, como intermediador, transporta, transfere, fazendo trocar e funcionar diversos sistemas, relacionando organizações e atores que de outro modo estariam desconectados. Ao colocar em circulação matérias e signos edifica uma tecnoesfera e uma psicoesfera.

O macrossistema de saúde brasileiro também cumpre os três requisitos mencionados anteriormente, mas com diferenças importantes. Ele não tem uma empresa de gestão da oferta e demanda dos fluxos, mas, sim, diversos centros de poder, porque é centralizado e descentralizado técnica e politicamente. Sua estrutura de poder dá a ele a condição de macro, porque envolve grande capacidade de regular fluxos (poder motriz) e de constituir redes de alianças e interesses políticos, econômicos e sociais (poder político). E, ao contrário do que aponta a literatura sobre macrossistema técnico, o macrossistema de saúde é bastante sensível às especificidades dos lugares. O que não o impede de cooptar e modular os demais sistemas técnicos e práticas em saúde.

Como núcleo central político e gestor, podemos compreender o SUS como sinônimo do macrossistema de saúde brasileiro, ainda que não justaposto ou coextensivo à totalidade dos sistemas técnicos que comunica ou ao conjunto de suas redes e componentes constitutivos.

$\bigcirc$ macrossistema de saúde brasileiro contém muitas organizações cujas finalidades e vínculos são os mais variados. Mas existem atores dominantes no macrossistema que são justamente aqueles que o regulam, o controlam e o gerenciam do ponto de vista técnico, político, financeiro e normativo. No caso do macrossistema de saúde brasileiro os atores hegemônicos 
têm sido: (i) entes estatais planejadores, gestores e financiadores do sistema (Ministério da Saúde e secretarias estaduais, do Distrito Federal e municipais de saúde); (ii) instituições reguladoras (nacionais, como as vigilâncias sanitárias e a Agência Nacional de Saúde Suplementar (ANS), e internacionais, como a Organização Mundial da Saúde (OMS) e a Organização Pan-Americana da Saúde (Opas)); (iii) o mercado, tanto por conta da atuação de grandes empresas multinacionais produtoras e fornecedoras dos insumos e equipamentos do sistema (indústria farmacêutica e de equipamentos médico-hospitalares), quanto pela atuação de grupos privados de seguradoras, planos de saúde e prestadores de serviços assistenciais (de atenção básica, hospitalares, ambulatoriais; de apoio diagnóstico e terapêutico); e (iv) profissionais de saúde, sobretudo, a corporação médica.

O SUS é um macrossistema de saúde por ser um conjunto de sistemas técnicos extremamente heterogêneo, ter um caráter marcadamente gerencial e de gestão de redes e por demandar para seu funcionamento componentes físicos de larga escala, como hospitais, hospitais de clínicas, hospitais universitários, edifícios administrativos, universidades, laboratórios farmacêuticos, laboratórios de apoio diagnóstico e terapêutico, e outros. O SUS vincula sistemas como os de: (i) Transporte: ambulâncias e motocicletas para atendimento móvel da rede do Serviço de Atendimento Móvel de Urgência (Samu), rede frio de distribuição viária de vacinas, barcos para unidades fluviais de atendimento médico do Programa Saúde da Familia, barcos hospitais, Ouvidoria Itinerante Fluvial, contratos com empresas aéreas para transporte aéreo de órgãos e de radiofármacos; (ii) Telecomunicações: centrais de regulação, serviços de atendimento móvel de urgência e emergência, sistema de informação e comunicação interligado entre unidades e órgãos de governos municipais, estaduais e federais; (iii) Sistema de Defesa, como os serviços e unidades de saúde das Forças Armadas brasileiras (campanhas de saúde, hospitais, laboratórios e reatores multipropósito'), sistema de vigilância sanitária e de defesa civil com os quais o SUS estabelece fortes vínculos.

Já uma face mais imaterial do macrossistema de saúde brasileiro é a integração de seus vários sistemas de informação voltados para a gestão e organização dos serviços de saúde em escala nacional, cujo principal nó articulador é o Departamento de Informática do SUS (Datasus/MS), como exemplos: Sistema de Informação Hospitalar (SIH), Sistema de Informação Ambulatorial (SAI), Sistema de Informação da Atenção Básica (Siab), Cadastro Nacional dos Estabelecimentos de Saúde (Cnes), Sistema Integrado de Informatização de Ambiente Hospitalar (Hospub), Sistema de Comunicação de Informação Hospitalar e Ambulatorial (Ciha), Sistema de Informações Hospitalares Descentralizado (ClHD), Sistema de Informação do Câncer do Colo do Útero (Siscolo), Sistema de Informação do Câncer de Mama (Sismama), Sistema de Acompanhamento do Programa de Humanização no Pré-Natal e Nascimento (Sisprenatal), Sistema de Gestão Clínica de Hipertensão Arterial e Diabetes Mellitus da Atenção Básica (Sishiperdia), Sistema de Informação do Programa Nacional de Imunizações (SI-PNI), Sistema Nacional de Gestão da Assistência Farmacêutica do SUS (Sistema Hórus), Cartão Nacional de Saúde (Cartão SUS) e Sistema de Informações sobre Orçamento Público em Saúde (Siops).

1 Reator Multipropósito Brasileiro (RMB) é um reator binacional que, em parceria com a Argentina, está sendo implantado no Centro Experimental Aramar da Marinha, em Iperó (SP). Alguns de seus propósitos serão a pesquisa e a aplicação na área de saúde, com, por exemplo, o desenvolvimento de radiofármacos. 
O setor privado da saúde é diverso e apresenta divergências entre seus atores, mas no geral ganha coesão em torno do objetivo comum em segmentar, fragmentar e lucrar com o sistema de saúde em benefício de usos e interesses corporativos. Destacando-se os planos e seguros de saúde, principalmente pelos vínculos com o capital financeiro e por disporem crescentemente de redes próprias de serviços. Há também os prestadores de serviços de saúde do setor suplementar (não SUS) e os prestadores de serviços de saúde para o SUS (setor complementar), cujos principais atores são os hospitais e redes hospitalares (privados e filantrópicos sem fins lucrativos). Outro grupo do setor privado é formado pelas principais empresas produtoras e fornecedores de equipamentos, medicamentos e insumos biomédicos. E mais recentemente, os grupos gestores privados de serviços públicos de saúde, uma diversidade de organizações que incluem desde fundações universitárias, grupos hospitalares, Organizações Sociais de Saúde (OSS) e Organizações Não Governamentais (ONG), cada vez mais atuando em redes de atenção e serviços em saúde (em vários níveis da atenção) esses grupos têm gerido Unidades de Saúde da Familia, Centros de Saúde, Unidades Básicas de Saúde (UBS), Unidades de Pronto Atendimento (UPA) e hospitais.

Não é comum declarações públicas e oficiais de nenhum ator ou mesmo agente se posicionando anti-SUS ou contra o SUS, mesmo porque na realidade todos são favoráveis ao SUS, mas não a uma mesma concepção e projeto de sistema de saúde ${ }^{2}$. Traço característico da hegemonia do SUS como macrossistema de saúde: tanto um como outro campo de força precisam do SUS, ainda que sob intencionalidades distintas e por vezes antagônicas, como o núcleo organizador da sistematicidade do macrossistema de saúde: planejando, gerindo, financiando, regulando e normatizando.

Os grandes meios de comunicação, como conglomerados comerciais que são, não se posicionam mais explicitamente a uma ou outra concepção de SUS, mas diariamente servem aos interesses de grupos econômicos privados, seus principais financiadores, não apenas por meio de peças publicitárias e matérias pagas, mas também pela produção de uma psicoesfera sutil mediante notícias, matérias e coberturas jornalísticas que continuamente amplificam e exacerbam os erros e pontos negativos do SUS público e universal. Uma demonização que nunca veicula as conquistas, acertos e possibilidades, e quando o faz jamais dá os créditos. Uma psicoesfera que tem desconstruído o SUS público e universal.

A questão em torno do problema do tamanho como indicativo para o caráter macro de um sistema técnico deve se atentar à combinação de uma dada técnica e a capacidade de uma organização em gerir a expansão da potência dessa técnica, mais politicamente do que comercialmente. $\bigcirc$ SUS integra e coloca em relação diversas redes e sistemas técnicos, fazendo dele um grande comunicador. Um macrossistema dual (público e privado) que fundamenta redes de poder: tanto de potência de circulação dos fluxos de saúde, como de interesses políticos. Como macrossistema, o SUS apresenta a tendência em romper toda sorte de fronteiras: políticas,

2 Este é o caso do Congresso Nacional brasileiro, no qual existem duas "frentes pela saúde", ambas a favor do SUS: uma em defesa deste como sistema público e direito social (pela universalização do direito à saúde pública) e outra de parlamentares que fomenta sua privatização e mercantilização, ainda que financiado pelo Estado, defendendo sua cobertura universal, mas segmentada e fragmentada em função dos níveis desiguais das classes sociais pagadoras e da divisão da participação e responsabilidade do Estado e dos atores do mercado segundo a distinção dos sistemas (ou componentes destes) em mais ou menos rentáveis e lucrativos. 
econômicas, ideológicas e de conhecimento. O SUS é macro em função de integrar técnica e politicamente o território brasileiro e de envolver, de uma maneira ou de outra, a população em sua totalidade, constituindo infraestruturas da vida cotidiana brasileira.

\section{O SUS como força estruturante do macrossistema de saúde brasileiro}

O SUS é responsável pelo pagamento de cerca de $80 \%$ do total de partos realizados no Brasil em maternidades públicas ou mistas, sendo que os $20 \%$ restante corresponde aos partos realizados na rede privada pagos por meio de plano de saúde ou desembolso direto. A rede hospitalar de atenção ao parto e nascimento no país é bastante heterogênea e regionalmente muito desigual, apresentando vazios assistenciais que obrigam deslocamentos para acesso à rede $^{3}$. Parcela significativa das maternidades não apresenta o "conjunto completo de medicamentos e equipamentos mínimos necessários aos atendimentos de emergência, tanto para a mulher como para o recém-nascido" (Leal, 2014, p. 3).

○ campo da saúde como um todo constitui importante setor da economia brasileira, sendo que em termos de emprego representa 4,3\% da população ocupada gerando cerca de $10 \%$ da massa salarial do conjunto de trabalhadores com carteira assinada, sem contar o grande contingente de profissionais diplomados que são acrescidos anualmente ao sistema. $\bigcirc$ setor saúde no Brasil apresenta por volta de 3,9 milhões de postos de trabalho: 2,6 milhões com vínculos formais, 690 mil sem carteira assinada e 611 mil profissionais autônomos. A predominância do binômio médicos/enfermagem que vigorou durante décadas - somando cerca de $80 \%$ da força de trabalho do setor saúde - tem sido pouco a pouco substituído por equipes multidisciplinares a partir de novas especialidades e de outras profissões, como dentistas, farmacêuticos, biólogos, nutricionistas, psicólogos, fisioterapeutas, terapeutas ocupacionais, além de engenheiros, economistas e sociólogos (Machado; Oliveira; Moyses, 2011). Segundo De Lavor, Dominguez e Machado (2011), o setor gera direta e indiretamente cerca de 12 milhões de empregos e é responsável por mais de $8 \%$ do Produto Interno Bruto brasileiro, superando até mesmo a agropecuária.

Não sendo somente um sistema de assistência médica e hospitalar, mas um sistema que articula prevenção, promoção, proteção, recuperação e reabilitação em saúde, o SUS é um macrossistema que está presente no cotidiano da população no Brasil como um quadro global da técnica instrumental constituído por sistemas técnicos de alimentação, mais ou menos extensos e integrados. Tal como os demais macrossistemas, caracterizados por uma técnica vinculada a uma finalidade mais específica, como o fornecimento de energia, de água e de informação (Braun; Joerges, 1992), a saúde (individual/assistencial, coletiva/saúde pública) é a finalidade específica do macrossistema de saúde brasileiro, ainda que busquem reduzi-lo à concepção limitada de saúde como mera ausência de doenças (uma de suas muitas dimensões).

3 Essa deficiência na rede de maternidades do SUS é mais acentuada nas regiões Norte e Nordeste, seguidas da região Centro-Oeste, um pouco melhor, enquanto nas regiões Sul e Sudeste (região concentrada) os estabelecimentos dessa rede são mais estruturados, apresentando níveis iguais ou mesmo superiores àqueles verificados na rede privada. 
Cerca de 40\% da compra de medicamentos no Brasil é feita pelo SUS (Alves, 2009). Fazem parte do SUS atualmente 19 laboratórios públicos ${ }^{4}$ para desenvolvimento e produção de medicamentos, soros, vacinas e Dispositivos Intrauterinos (DIU). Segundo De Lavor, Dominguez e Machado (2011), os laboratórios públicos oficias produzem $80 \%$ das vacinas e 30\% dos medicamentos utilizados no SUS. Os autores destacam a presença da vigilância sanitária, cujas ações integram o SUS, em diversos locais como hospitais, clínicas, creches, espaços culturais, orfanatos, presídios, salões de beleza, supermercados e feiras visando garantir que produtos e serviços tenham qualidade e segurança em ramos como "de alimentos, medicamentos, saneantes (inseticidas, desinfetantes etc.), cosméticos, equipamentos para diagnóstico e tratamento de doenças, defensivos agrícolas, bem como serviços médicos, odontológicos, hospitalares e laboratoriais" (p. 13). O Sistema Nacional de Vigilância Sanitária (SNVS) é formado pelas Vigilâncias Sanitárias estaduais e municipais e é coordenado pela Agência Nacional de Vigilância Sanitária (Anvisa).

Embora $75 \%$ da população brasileira seja exclusivamente usuária do SUS ${ }^{5}$, os outros $25 \%$ que têm plano de saúde também utilizam o SUS em alguma medida, sobretudo, nas ações de prevenção (vigilância sanitária, campanhas e programas de imunização), de procedimentos de alta complexidade (como transplantes, medicamentos de alto custo), nos serviços de urgência e emergência, na pesquisa e desenvolvimento tecnológico, ou mesmo a partir dos profissionais de saúde acessados de forma privada (por meio de plano ou desembolso individual direto), como no caso dos médicos cuja melhor formação de especialistas no Brasil é proporcionada, de modo geral, pelos programas e instituições públicas custeados pelo Estado.

Não existem "dados confiáveis sobre o número de médicos e especialistas empregados pelas redes públicas federal, estaduais e municipais, número de vínculos, jornadas e carga horária desses profissionais", mas a grande maioria dos médicos atua em mais de um emprego,

4 Segundo dados da Associação de Laboratórios Farmacêuticos Oficiais do Brasil - Alfob (Laboratórios [...], 2014), são os seguintes os 19 laboratórios públicos oficiais: Instituto de Tecnologia em Fármacos - Farmanguinhos (RJ); Bio-Manguinhos (RJ); Instituto Vital Brazil (RJ); Laboratório Farmacêutico da Marinha - LFM (RJ); Laboratório Químico-Farmacêutico da Aeronáutica - Laqfa (RJ); Laboratório Químico Farmacêutico do Exército - Lqfex (RJ); Fundação Ezequiel Dias - Funed (MG); Fundação para o Remédio Popular - Furp (SP); Instituto Butantan (SP); Centro de Produção e Pesquisa de Imunobiológicos - CPPI (PR); Instituto de Tecnologia do Paraná - Tecpar (PR); Laboratório Farmacêutico do Rio Grande do Sul - Lafergs (RS); Bahiafarma (BA); Fundação Hemope (PE); Laboratório Farmacêutico do Estado de Pernambuco Governador Miguel Arraes - Lafepe (PE); Laboratório Industrial Farmacêutico de Alagoas S.A. - Lifal (AL); Núcleo de Pesquisa em Alimentos e Madicamentos - Nuplam (RN); Indústria Química do Estado de Goiás S/A - lquego (GO).

5 Adota-se aqui a relação entre 75\% SUS e 25\% planos privados de saúde e desembolsos diretos para expressar de uma forma geral a dimensão da cobertura pública e privada de saúde no país. Contudo, essa relação apresenta desigualdades sociais (segundo classe social e poder aquisitivo) e regionais: diferenças entre as regiões do país, os municípios capitais $e$ as regiões metropolitanas e interioranas (sendo que a cobertura do SUS decresce conforme aumenta o porte populacional do município). Segundo dados do Instituto Brasileiro de Geografia e Estatística (IBGE, 2014), da Agência IBGE notícias (PNS [...], 2015) e da ANS (Dados [...], 2014), a porcentagem da população coberta por planos de saúde vem aumentando, com uma média brasileira de 18,24\% em 2000, enquanto em 2012 chega em 25,10\% a população com planos de saúde, dada a seguinte distribuição regional: 10,86\% da população na região Norte; $12,09 \%$ no Nordeste; 18,81\% na região Centro-Oeste; $23,89 \%$ no Sul; e 38,07\% na região Sudeste, com os dois extremos representados pelo estado de São Paulo, onde 43,6\% da população dispõem de planos privados de saúde, e pelo Acre, onde esse percentual é o menor da federação, com 5,6\%. Contudo, a tendência de aumento do desemprego e de perdas salariais leva ao aumento da cobertura pública em detrimento da privada. 
sendo muito comum que esses profissionais trabalhem jornadas tanto na rede pública SUS quanto na rede privada ${ }^{6}$, estima-se que 55\% dos médicos brasileiros trabalham no SUS (Scheffer; Cassenote; Biancarelli, 2013, p. 165).

Uma face bem visível do macrossistema de saúde brasileiro é a Política Nacional de Urgências e Emergências da qual um dos sistemas integrantes é o Serviço de Atendimento Móvel de Urgência (Samu). Esse serviço funciona 24h e é controlado por 177 Centrais de Regulação das Urgências que organizam o atendimento em 2.360 municípios brasileiros com cobertura populacional de cerca de 130 milhões de habitantes, por meio de equipes de profissionais de saúde (médicos, enfermeiros, auxiliares de enfermagem e socorristas) com apoio de 2.000 ambulâncias, além de motocicletas, barcos e helicópteros. A Rede de Atenção às Urgências e Emergências também organiza e coordena ações de urgência nas UPA, Unidades Básicas de Saúde (UBS) nas unidades de pronto-socorro dos hospitais e no atendimento pós-hospitalar. Também faz parte dessa rede, desde 2009, o programa de Unidades de Pronto Atendimento 24h (UPA), que prevê o funcionamento de 462 unidades, sendo que 256 já estavam em funcionamento em 2012 (Brasil, 2012).

Em 2009, registrou-se no Brasil a existência de 105.270 estabelecimentos de saúde, sendo 3.741 desativados, 4.080 extintos, $96.450 \mathrm{em}$ atividade e $999 \mathrm{em}$ atividade parcial. Dos 94.070 estabelecimentos de saúde classificados como unidades assistenciais em 2009 (conceito que o IBGE manteve para preservar a série histórica de seus levantamentos) 752.023 (ou 55,3\% do total) apresentavam natureza jurídica pública, sendo de administração municipal em quase sua totalidade (95,6\% das unidades), e somente 2,5\% estadual e 1,8\% federal (IBGE, 2009). $\bigcirc$ que expressa a política de municipalização da assistência à saúde no Brasil prevista com a criação do SUS em 1988.

Dos estabelecimentos de natureza jurídica privada predominavam aqueles com fins lucrativos $(90,6 \%)$ face os privados sem fins lucrativos (9,4\%). Tem ocorrido uma tendência de diminuição na participação do conjunto de estabelecimentos privados (com ou sem fins lucrativos) que estabelecem vínculos com o SUS, de 30,6\% em 2005 para 27,1\% em 2009. Quanto à fonte de financiamento dos estabelecimentos, predomina os que fazem referência ao SUS, com 67,2\% em 2009, apresentando diminuição em relação ao anos de 2005 quando o SUS representava a fonte de financiamento de $70,9 \%$ dos estabelecimentos de saúde (IBGE, 2009) ${ }^{8}$.

6 De acordo com o IBGE (2009), desde 1999 a rede privada tem contado com a maioria dos postos de trabalho médico, sendo que nas regiões Sudeste, Sul e Centro-Oeste predomina o número de postos de trabalho médico no setor privado (com respectivamente 58,5\%, 64,4\% e 54,9\%), enquanto nas regiões Norte e Nordeste predominam os postos médicos no setor público (com respectivamente 62,2\% e 54,1\% do total dos postos de trabalho).

7 De acordo com documento do IBGE (2009), os levantamentos e as sistematizações de estatísticas relativas à saúde em escala nacional e periodicidade anual tiveram início a partir de 1931, com o Serviço de Estatística da Educação e Saúde do Sistema Estatístico Nacional. A Pesquisa de Assistência Médico-Sanitária do IBGE utiliza o conceito de unidade assistencial e contempla todos os estabelecimentos de saúde do país que atuam na assistência à saúde tanto individual como coletiva "com um mínimo de técnica apropriada, públicos ou privados, com ou sem fins lucrativos, [...] em regime ambulatorial ou de internação, inclusive os de diagnose, terapia e controle regular de zoonoses" (IBGE, 2009, p. 13). Temos como exemplos: Postos de Saúde; Centros de Saúde; Clínicas ou Postos de Assistência Médica; Prontos-Socorros; Unidades Mistas; Hospitais (inclusive os de corporações militares); Unidades de Complementação Diagnóstica e/ou Terapêutica; Clínicas Odontológicas, Radiológicas e de Reabilitação; e Laboratórios de Análises Clínicas.

8 É importante frisar que no levantamento das Pesquisas AMS do IBGE não estão contemplados: os consultórios particulares de profissionais de saúde autônomos (médicos, psicólogos, enfermeiros, dentistas etc.); pequenas clínicas 
O crescimento da rede de materialidades do SUS ocorre de modo mais acelerado na última década, passando de 50.902 em agosto de 2005 para um total de 75.979 estabelecimentos públicos de saúde de um total de 273.079 estabelecimentos registrados em janeiro de 2015, sendo: 193.760 privados, 2.921 filantrópicos e 419 vinculados a sindicatos. Segundo os tipos de unidades prestadoras, em janeiro de 2015 se verifica a seguinte composição: (i) unidades com internação (hospital) - 5.819 vinculadas ao SUS e 3.770 privadas; (ii) unidades sem internação (ambulatoriais) - 73.996 ligadas aos SUS e 175.763 privadas; (iii) unidades de SADT - 23.218 do SUS e 31.218 privadas; (iv) unidades de urgência e emergência - 9.819 vinculadas ao SUS e 3.597 particulares; (v) todas as 11.102 unidades de vigilância epidemiológica e/ou sanitária vinculadas ao SUS; e (vi) 5.369 unidades de farmácia ou cooperativa vinculadas ao SUS (sob administração direta ou não) que realizam dispensação de medicamentos, tanto do componente básico e essenciais (como Programa Farmácia Popular) como do componente dos excepcionais (alto custo) previstos na Política Nacional de Assistência Farmacêutica?.

\section{SUS como macrossistema: infraestruturas da vida cotidiana e sentidos de suas sistematicidades}

Os macrossistemas técnicos se caracterizam por constituírem infraestruturas da vida cotidiana (Gras, 1997, 2001), um conjunto de redes às quais o homem moderno está ligado e do qual sem perceber tornou-se extremamente dependente, desconhecendo também onde estão situados os centros dessas redes e menos ainda a maneira pela qual são organizadas e quais os objetivos dessa expansão técnica e científica. Cotidiano compreendido por Gras (1992) como modo de vida, como maneira de ser no mundo expressa na vida de todos os dias.

Além do comprimento, largura, profundidade e tempo, Santos (1999) propõe o cotidiano como a quinta dimensão do espaço banal, o qual remete às noções de copresença, de vizinhança e de território compartido. Copresença e intercâmbio são condicionados pelas infraestruturas presentes e suas normas e possibilidades de uso. Um conjunto de materialidades "que é, ao mesmo tempo, uma condição para a ação; uma estrutura de controle, um limite à ação; um convite à ação. Nada fazemos hoje que não seja a partir dos objetos que nos cercam" (Santos, 1999, p. 257). Compreendemos a dimensão espacial do cotidiano como uma mescla de pragmatismo e emoção a partir dos lugares e das pessoas juntas, em situação de vizinhança (Santos, 2000).

No lugar - um cotidiano compartido entre as mais diversas pessoas, firmas e instituições - cooperação e conflito são a base da vida em comum. Porque cada qual exerce uma ação própria, a vida social se individualiza; e porque a contigui-

ambulatoriais privadas; estabelecimentos com atendimento de clientela restrita (como gabinetes dentários e ambulatórios médicos para atendimento de alunos e funcionários em escolas e empresas, particulares e privadas); estabelecimentos dedicados exclusivamente ao ensino e à pesquisa sem atendimento público; e aqueles estabelecimentos criados provisoriamente em função de alguma campanha de saúde. Daí a diferença na relação entre financiamento público (SUS) e privado na rede de estabelecimentos do IBGE quando comparada com a relação global de gastos com saúde no Brasil, na qual $45 \%$ do total são gastos públicos, enquanto os gastos privados correspondem a $55 \%$.

9 Informações organizadas a partir de compilação própria baseada no levantamento de dados junto ao Cadastro Nacional de Estabelecimentos de Saúde (CNES), disponível na página http://www2.datasus.gov.br/DATASUS/index. php?area $=0204 \varepsilon$ id $=6906$. 
dade é criadora de comunhão, a política se territorializa, com o confronto entre organização e espontaneidade. O lugar é o quadro de uma referência pragmática ao mundo, do qual the vêm solicitações e ordens precisas de ações condicionadas, mas é também o teatro insubstituível das paixões humanas, responsáveis, através da ação comunicativa, pelas diversas manifestações da espontaneidade e da criatividade (Santos, 1999, p. 258).

O SUS constitui infraestruturas da vida cotidiana. Em maior ou em menor grau, mas em alguma medida, se faz presente no dia a dia de todos, ainda que não tenhamos consciência dessa dependência e dessa incidência. Compreendê-lo como macrossistema de saúde permite apreendê-lo como dimensão espacial do cotidiano e desvendar as intencionalidades e projetos que acompanham os discursos e as ações de atores e agentes no campo da saúde.

Segundo levantamento (IPEA, 2011), 34,3\% da população brasileira afirmou nunca ter usado o SUS. Para De Lavor, Dominguez e Machado (2011), é muito pouco provável que esse dado faça sentido e que corresponda à realidade. O SUS está presente no cotidiano de toda a população residente no Brasil, contudo também se faz presente na vida diária das pessoas a produção de uma invisibilidade do SUS que responde a alguns interesses e intencionalidades, sobretudo daqueles vinculados à mercantilização e privatização da saúde.

A produção dessa invisibilidade opera não para extinguir o SUS, em todas as suas dimensões e em sua totalidade, mas muito pelo contrário, para levá-lo a uma sistematicidade outra que não aquela projetada pelos movimentos de redemocratização e pelo Movimento da Reforma Sanitária Brasileira incorporados pelo texto da Constituição de 1988, conforme seu Artigo 196 que define: "A saúde é direito de todos e dever do Estado, garantido mediante políticas sociais e econômicas que visem à redução do risco de doença e de outros agravos e ao acesso universal e igualitário às ações e serviços para sua promoção, proteção e recuperação" (Brasil, 2008, p. 125). A esse princípio está subjacente a concepção ampliada de saúde e um sistema público de saúde operador de inclusão social e de transformação e emancipação políticas.

Como infraestrutura da vida cotidiana, o SUS está presente na vida de todas as pessoas residentes no Brasil mesmo que não tenhamos consciência disso, ainda que haja a produção deliberada de sua invisibilidade, de achatamento da sua real dimensão ou de ocultamento de algumas de suas faces e interfaces. Produção de uma psicoesfera ${ }^{10}$ a serviço de interesses particulares de ordem corporativa que beneficia grupos econômicos que jogam com a privatização e mercantilização da saúde.

Na produção desse senso comum, o SUS é sinônimo de público estatal (de poucos recursos, precariedade, má gestão e sistema de saúde para pobres), enquanto o privado é exclusivamente privado (sinônimo de excelência, eficiência e boa administração e gestão). Enquanto uma grande parcela da população $(75 \%)$ depende única e diretamente do SUS, outra parcela (25\%) também usufrui de ações da esfera mais privada e mercantil da saúde, sobretudo no aspecto médico-assistencial individual (planos e seguros de saúde, além de desembolsos diretos

10 Psicoesfera é aqui compreendida como o "reino das ideias, crenças, paixões e lugar da produção de um sentido", que, fazendo parte do "meio ambiente, desse entorno da vida", fornece "regras à racionalidade" e estimula "o imaginário" (Santos, 1999, p. 204). 
por serviços privados), que é um dos elementos do macrossistema de saúde. Toda a população brasileira ou aqui residente é coberta e depende em maior ou menor grau das ações do SUS, ou seja, como totalidade e estrutura, o território brasileiro é SUS dependente.

Infraestrutura do cotidiano que expressa o caráter quase obrigatório, displicente e despercebido com que atividades, juízos, atos, gestos, ideias e acontecimentos do dia a dia sustentam o macrossistema, como: comer alimentos inspecionados e liberados pela vigilância sanitária; virar um vaso vazio de cabeça para baixo para evitar criadouro de inseto transmissores de doenças; usar preservativos para evitar doenças sexualmente transmissíveis ou gravidez indesejável; nascer e morrer em hospitais.

$\bigcirc$ macrossistema de saúde impressiona pelos seus grandes feitos. É macro pelos seus feitos notáveis e pelos seus feitos corriqueiros e não notados que, no conjunto, o torna um sistema hegemônico no território.

De Lavor, Dominguez e Machado (2011) identificaram que falta um comprometimento maior dos gestores do sistema para evidenciar o tamanho real do SUS e uma má vontade da grande mídia em relação ao sistema, o que se deve em boa medida à orientação ideológica desses grupos de comunicação que têm postura privatista e demonizam o SUS alardeando que o que é público não funciona.

Como alguns casos desse SUS que não se vê, mas que está presente no cotidiano da população brasileira, sem que boa parte das pessoas tenha consciência dele, podemos citar: as ações de vigilância em saúde; as campanhas de imunização; os procedimentos de alta complexidade, como transplantes de órgãos; programas de prevenção e tratamento de reconhecimento internacional, como é o caso das vacinas com o programa Nacional de Imunização e o programa de prevenção ao HIV e de tratamento para a Aids (desde 1996 é garantido o acesso universal e gratuito aos antirretrovirais); produção de tecnologia e conhecimento em instituições públicas de pesquisa e ensino; e a saúde como importante setor na economia brasileira, tanto industrial quanto de serviços. Além de grupos e comunidades de usuários, movimentos sociais e sociedade civil organizada que atuam junto ao macrossistema buscando sentidos mais comunitários e emancipatórios a partir de uma concepção ampliada de saúde.

\section{Considerações finais}

É por seus grandes feitos e sua inserção na vida cotidiana, nem sempre visível, que o SUS pode ser considerado macro e hegemônico no território, porque notável e extraordinário, mas também corriqueiro e despercebido. Cotidiano dos grandes eventos, do acontecer rotineiro, dos afazeres diários e, também, do acontecer diferencial e das invisibilidades: tanto de silenciamentos e ocultamentos, próprios da produção deliberada de um SUS que "não se vê" a serviço de interesses corporativos, como da relativa limitação do SUS em lidar, incorporar e comunicar mais intensamente práticas e saberes locais e populares, silenciando sobre heranças culturais e institucionais portadoras de diferenças transformadoras e capazes de imprimir novas sistematicidades ao macrossistema.

A análise geográfica do macrossistema de saúde permite compreender que a solidariedade organizacional que confere a força sistêmica à difusão das técnicas, constituindo a atual unicidade da técnica e a emergência de macrossistemas, não é emanada da técnica em si ou da 
solidariedade entre os objetos por eles mesmos. Emana da solidariedade da vida em sociedade e de seus sistemas de ações. A hegemonia nos atuais macrossistemas, entre eles o macrossistema de saúde brasileiro, fundamenta-se no controle simultâneo das condições objetivas e subjetivas da ação, por meio da sistematicidade dominante imprimida na tecnoesfera e na produção de uma psicoesfera correspondente ao seu projeto.

A atual sistematicidade impõe solidariedades externas aos lugares, comandadas por atores que conseguem estabelecer ações nas distintas escalas (global, nacional, regional e local) e instâncias da vida (social, cultural, política e econômica).

O conceito de macrossistema de saúde promove uma compreensão dos usos do território vinculados às ações e aos sentidos da saúde por meio de pares dialéticos como Estado e mercado, interno e externo, novo e velho, dominado e insurgente, compreendendo o sistema de saúde em sua dualidade (como direito e bem social, campo de emancipação política, e como bem econômico e privado, campo de acumulação) e a saúde como conceito ampliado para além da mera assistência médico-hospitalar ou ausência de doença: saúde em suas dimensões política, econômica, social e cultural.

Ler o SUS como macrossistema de saúde se justifica para ampliar a compreensão sobre o sistema de saúde, abrangendo outros aspectos, variáveis, escalas e elementos envolvidos com a política e os serviços de saúde e que são decisivos para o seu funcionamento e rumo. A dimensão macro é o SUS, e isso nos leva a compreendê-lo para além de um sistema de saúde. Isso significa que o macrossistema parte do SUS e se funda nele, tem nele sua principal força estruturante e condicionante, mas vai além, porque abrange outros aspectos e elementos não relacionados diretamente ao SUS. É macro porque condiciona a política, o financiamento e as normas da saúde. Além disso, é o grande comunicador e integrador dos diversos serviços, redes e sistemas técnicos que extrapolam o campo da saúde. Sem o SUS, talvez não haveria um macrossistema de saúde brasileiro.

Utilizamos o termo SUS, como sinônimo e nome próprio do macrossistema de saúde, como estratégia para não corrermos o risco de dissimular o caráter eminentemente estatal da força estruturante, organizadora e financiadora desse macrossistema, contribuindo para explicitar sua base material e suas redes de poder, seus vínculos, fundamentos e sentidos mercantis e, sobretudo, sociais, e buscando ainda estabelecer e identificar os campos de força (interesses políticos, econômicos e sociais) presentes em seus discursos, intencionalidades, projetos e, especialmente, na imaginação do que seja esse macrossistema. Esse conceito permite ver, compreender e atuar no SUS como projeto em construção, processo que não está fechado, acabado ou definido.

Ademais, compreendê-lo como macrossistema de saúde faz com que qualquer mudança projetada ou desejada no seu movimento ou em algum de seus subsistemas requeira a definição de estratégias de ação em diversas escalas e instâncias da vida. $\bigcirc$ conceito de macrossistema de saúde é útil para abrir, expandir, e não para fechar, mas para iluminar e projetar estratégias que considerem o seu poder inercial de arrasto e as sistematicidades em disputa pelo seu comando e futuro.

Um macrossistema, qualquer que seja, é sensível aos lugares, impossível não sê-lo. É plástico porque sofre condicionamento das distintas situações geográficas que produz e pelas quais é produzido. É possível afirmar que o conteúdo dos lugares invade, cada vez mais, os 
macrossistemas, transformando-os e exigindo deles novos comportamentos técnicos, sociais, políticos e econômicos. A sensibilidade do macrossistema de saúde brasileiro às especificidades dos lugares se deve à sua permeabilidade às políticas de baixo para cima. É fruto das forças políticas criadoras e emancipadoras constitutivas do SUS, presentes desde sua gênese com - Movimento da Reforma Sanitária brasileira e, além deste, de outros movimentos sociais organizados (em prol da democracia, da agroecologia, da cidadania, da saúde dos negros, dos direitos humanos, da saúde da mulher e da criança, da reforma agrária, entre outros).

De modo geral, os principais autores que trabalharam com o conceito de macrossistema técnico o fizeram numa perspectiva de cima para baixo, como verticalidade, o que se deve à definição que consagrou esses estudos de que os macrossistemas tendem a centralizar politicamente e a ser insensíveis aos lugares. De uma perspectiva geográfica, acrescentaríamos que toda difusão, para se estender no espaço e durar no tempo, tem que mudar, tem que lidar e sempre se adequar aos lugares, em alguma medida, ao território que se impõe, seja como condicionante, como facilitador ou como obstáculo. $\bigcirc$ território usado como sinônimo de espaço banal, território usado por todos, é limite e limiar de toda difusão. Em sua difusão, o macrossistema não inclui tudo, não pode tudo. E sendo fundamento material das redes de poder, como todo poder, ao ser exercido, é confrontado e sofre resistência.

Daí a importância de apreendê-lo como um sistema de alianças e agenciamentos, o que permite a uma dada técnica se fazer valer como indispensável e superior a qualquer outra considerada, construindo concomitantemente tecnoesfera (infraestrutura e rede de materialidades) e psicoesfera (ideários, sentidos, valores e visões de mundo). Um conjunto estruturado tanto concreta como abstratamente, imanente e transcendente. Um sistema técnico que caracteriza uma ação política por ser uma escolha de sociedade, e a maneira pela qual, sistematizando objetos e ações, assegura a durabilidade e a difusão espacial dessa escolha.

\section{Referências}

ALVES, T. N. P. Política Nacional de Medicamentos: análise a partir do contexto, conteúdo e processos envolvidos. Tese (Doutorado em Medicina Social) - Instituto de Medicina Social, Universidade do Estado do Rio de Janeiro, Rio de Janeiro, 2009.

BRASIL. Ministério da Saúde. A implantação das Redes Temáticas de Atenção à

Saúde: avanços, desafios e perspectivas. Apresentação da Secretaria de Atenção à Saúde do Ministério da Saúde (SAS/MS) na Comissão Intergestores Tripartite. Brasília: MS, 2012.

Constituição da República Federativa do Brasil. 5. ed. rev. ampl. e atual. São Paulo: Ed. Revista dos Tribunais, 2008. (Obra coletiva de autoria da Editora Revista dos Tribunais).

. Lei n. 8.080, de 19 de setembro de 1990. Dispõe sobre as condições para a promoção, proteção e recuperação da saúde, a organização e o funcionamento dos serviços correspondentes e dá outras providências. Diário Oficial da União, Brasilia, DF, 19 set. 1990. 
BRAUN, I.; JOERGES, B. Techiniques du quotidien et macrosystèmes techniques. In: GRAS, A.; JOERGES, B.; SCARDIGLE, V. Sociologie des techniques de la vie quotidienne. Paris: Harmattan, 1992. p. 69-86.

CATAIA, M. Poder, política e uso do território: a difusão do macrossistema elétrico nacional. In: COLOQUIO INTERNACIONAL DE GEOCRÍTICA - EL CONTROL DEL ESPACIO Y LOS ESPACIOS DE CONTROL, 13., 2014, Barcelona. Anais... Barcelona: CIG, 2014. p. 1-17.

CEBES. Centro Brasileiro de Estudos da Saúde. Manifesto do Centro Brasileiro de Estudos de Saúde em defesa do direito universal à saúde - saúde é direito e não negócio, ago. 2014.

DADOS gerais. ANS, jul. 2014. Disponível em: http://www.ans.gov.br/perfil-do-setor/dados-gerais. Acesso em: 9 dez. 2017.

DE LAVOR, A.; DOMINGUEZ, B.; MACHADO, K. O SUS que não se vê - Sistema faz parte do dia a dia de todos os brasileiros, mas não é reconhecido em suas diversas dimensões. In: RADIS - COMUNICAÇÃO E SAÚDE, 14., 2011, Rio de Janeiro. Anais... Rio de Janeiro: Ensp/Fiocruz, 2011. p. 9-17.

ELLUL, J. Le système technicien. Paris: Calmann-Lévy, 1977.

GRAS, A. L'illusion de la fatalité technique. L'écologiste, Dossier: Sciences et Techniques, n. 5, p. 26-33, 2001.

Les macro-systèmes techniques. 1. ed. Paris: Presses Universitaires de France, 1997. (Collection Que sais-je?)

Grandeur et dépendance - Sociologie des macrosystèmes techniques. Paris: PUF, 1993.

. Le bonheur, produit sergele. In: GRAS, A.; MORICOT, C. Technologies du quotidien, la complainte du progrès. Paris: Autrement, 1992.

HUGHES, T. P. La evolución de los grandes sistemas tecnológicos. In: THOMAS, H; BUCH, A. (Org.). Actos, actores y artefactos: sociología de la tecnología. Bernal: Universidad Nacional de Quilmes, 2008. p. 101-44.

Networks of Power: Electrification in Western Society, 1880-1930. Baltimore: Johns Hopkins University Press, 1983.

HUGHES, T. P.; MAYNTZ, R. (Ed.). The development of large technical systems. Frankfurt am Main/Campus Verlag/Boulder Colorado: Westview Press, 1988.

IBGE. Instituto Brasileiro de Geografia e Estatística. PNS - Pesquisa Nacional de Saúde. Rio de Janeiro: IBGE, 2015. Disponível em: https://agenciadenoticias.bge.gov.br/ media/com_mediaibge/arquivos/246c87fe818b77f8047c8dled612alfl.pdf. Acesso em: 9 dez. 2017. 
Estatísticas da Saúde - Assistência Médico-Sanitária 2009. Rio de Janeiro: IBGE, 2009.

IPEA. Instituto de Pesquisa Econômica Aplicada. Sistema de Indicadores de Percepção Social (SIPS). Organização Fábio Schiavinatto. Brasília, DF: Ipea, 2011.

JOERGES, B. Large technical systems: concepts and issues. In: MAYNTZ, R.; HUGHES,

T. P. (Ed.). The development of large technical systems. Frankfurt am Main/ Campus Verlag/Boulder Colorado: Westview Press, 1988.

LABORATÓRIOS Associados. Alfob, jul. 2014. Disponível em: http://www.alfob.org/portugues/site/laboratorios. Acesso em: 9 dez. 2017.

LEAL, M. do C. (Coord.). Nascer no Brasil: Inquérito Nacional sobre Parto e Nascimento. Rio de Janeiro: ENSP/Fiocruz/CNPq/Faperj, 2014. (Sumário Executivo Temático da Pesquisa).

LIMA, J. C. F. O Banco Mundial, a Organização Mundial de Saúde e o "novo universalismo" ou a "cobertura universal de saúde". In: PEREIRA, J. M. M.; PRONKO, M. (Org.). A demolição de direitos: um exame das políticas do Banco Mundial para a educação e a saúde (1980-2013). Rio de Janeiro: Escola Politécnica de Saúde Joaquim Venâncio/ Fiocruz, 2014. p. 233-253.

LOBATO, L. de V. C.; GIOVANELLA, L. Sistemas de Saúde: origens, componentes e dinâmica. In: GIOVANELLA, L. et al. (Org.). Políticas e Sistema de Saúde no Brasil. 2. ed. Rio de Janeiro: Fiocruz, 2012. v. 1. p. 89-120.

MACHADO, M. H.; OLIVEIRA, E. dos S. de; MOYSES, N. M. N. Tendências do mercado do trabalho em saúde no Brasil. In: PIERANTONI, C.; DAL POZ, M. R.; FRANÇA, $\mathrm{T}$. (Org.). O trabalho em saúde: abordagens quantitativas e qualitativas. Rio de Janeiro: Cepesc, 2011. v. 1. p. 103-116.

NORONHA, J. C. de. Cobertura universal de saúde: como misturar conceitos, confundir objetivos, abandonar princípios. Cadernos de Saúde Pública, Rio de Janeiro, v. 29 , p. 847-849, maio 2013.

PNS 2013: três em cada quatro brasileiros costumam buscar atendimento médico na rede pública de saúde. Agência IBGE notícias, jun. 2015. Disponível em: https:// agenciadenoticias.ibge.gov.br/agencia-sala-de-imprensa/2013-agencia-de-noticias/ releases/10138-pns-2013-tres-em-cada-quatro-brasileiros-costumam-buscar-atendimento-medico-na-rede-publica-de-saude.html. Acesso em: 9 dez. 2017.

RAFFESTIN, C. Por uma geografia do poder. São Paulo: Ática, 1993[1980].

RIBEIRO, A. C. T. Teorias da Ação. Apostila com transcrição do Curso Teorias da Ação ministrado na Universidade Estadual de Campinas. Campinas: Unicamp, 2002.

RIBEIRO, L. H. L. Território e macrossistema de saúde: os programas de fitoterapia no Sistema Único de Saúde (SUS). Tese (Doutorado em Geociências) - Instituto de Geociências, Universidade Estadual de Campinas, Campinas, 2015. 
SANTOS, M. Por uma outra globalização: do pensamento único à consciência universal. 2. ed. Rio de Janeiro: Record, 2000.

A natureza do espaço: técnica e tempo - razão e emoção. 3. ed. São Paulo: Hucitec, 1999[1996].

SCHEFFER, M.; CASSENOTE, A.; BIANCARELLI, A. (Coord.). Demografia médica no Brasil: cenários e indicadores de distribuição. São Paulo: CFM/Cremesp, 2013. v. 2. 